\title{
Incorporating a Maple Project of Multi-Cultures Art in College Mathematics Teaching
}

\author{
Lina $\mathrm{Wu}^{1} \& \mathrm{Ye} \mathrm{Li}^{2}$ \\ ${ }^{1}$ Department of Mathematics, Borough of Manhattan Community College, The City University of New York, \\ New York, USA \\ ${ }^{2}$ Department of Mathematics, Central Michigan University, Mount Pleasant, USA \\ Correspondence: Lina Wu, Department of Mathematics, Borough of Manhattan Community College, The City \\ University of New York, New York, NY 10007, USA. Tel: 1-212-346-8601.
}

Received: May 20, 2018

Accepted: June 10, 2018 Online Published: June 18, 2018

doi:10.5539/jel.v7n5p42

URL: https://doi.org/10.5539/jel.v7n5p42

\begin{abstract}
Teaching mathematics by project-based learning (PBL) method on the use of educational technology offers an innovative teaching pedagogy at college. The "World Culture Art Created with Calculus Graphs of Equations" poster project was designed by the first author and was completed in the pilot Calculus course during the spring 2016 semester at Borough of Manhattan Community College in the City University of New York. This project was to guide students to use graphs of equations in the creation of recognizable national symbols from different countries with different cultures by the Maple technology. Students' graphing knowledge as well as their technical Maple skills were applied in the completion of this project. Students' creativity, freedom, and diversity in their mathematical thinking have been fostered. Students have learned that combining mathematics knowledge with technological skills can create innovation in art. The project increased students' awareness and appreciation of multi-cultures for a diversified student body in New York. Successful project outcomes in students' work shed light on effectiveness of this project-based learning (PBL) approach in mathematics education.
\end{abstract}

Keywords: Algebra, Calculus, cultural symbol, graphing knowledge, Maple software, multi-cultural approach, project-based learning, Trigonometry

\section{Introduction and Literature Reviews}

Mathematics knowledge of definitions, notations, formulas, and theories are too abstract and too complicated for some students to understand. Incomplete comprehension or misconception would cause students to lose interest in further learning. Moreover, it could create math anxiety. How to correct students' mathematical misconception (Li \& Li, 2008) and how to avoid misusing mathematical definitions (Edwards \& Ward, 2004) have been observed. How to overcome math anxiety (Furner \& Berman, 2003) has been studied. Educators and researchers have realized that the traditional way of lecturing on blackboard is not effective to improve students' conceptual understanding in depth and width.

In order to overcome problems that might impede in successful learning, educators have implemented a variety of teaching methods to improve effective teaching. One useful teaching strategy is to use modern technologies as educational tools to facilitate students' learning. For instance, a technology-enhanced pedagogical content knowledge (TPCK) development (Niess, 2005) was utilized to monitor difficulties and success in students' learning progress. Maple Software as a graphing tool in Linear Algebra course (Kilicman, Hassan, \& Husain, 2010) and in the sequence of Calculus courses (Devitt, 1993) has been implemented in classroom teaching. The web-oriented online homework platforms, such as MyMathLab, WebAssign, and WeBWork, have been established to monitor students' out-of-class exercises in mathematical remedial courses (Mestre, Hart, Rath, \& Dufresne, 2002; York, Hodge, \& Richardson, 2008; Zerr, 2007). In summary, modern technologies have been used as symbolic or numeric calculation tools, animated graphing tools, and interactive communication tools to create dynamic teaching.

Another barrier for student success in math learning is the lack of practice on how to apply theoretical knowledge to solve real-life problems. Even for some students with excellent grades in tests at school, they are unable to apply math in their daily-life situations. Students do not know how to build mathematical models in the 
real-life contexts. Students do not know how to apply academic knowledge for practise in reality as problem-solving skills.

In order to develop students' problem-solving skills, teachers are encouraged to integrate educational activities related to curriculum as a part of classroom teaching. The project-based learning (PBL) method as an innovative teaching pedagogy provides students an opportunity of learning by discovering, questioning, discussing and practicing on projects in real-life environments. Students' academic achievements by using PBL have been investigated (Ali, Akhter, Shahzad, Sultana, \& Ramzan, 2011; Goodnough \& Cahsion, 2003; SZ \& Eng, 2005; Tarmizi \& Bayat, 2010).

In this article, authors would like to share the experience on how to integrate PBL in Calculus teaching. The "World Culture Art Created with Calculus Graphs of Equations" poster was designed by the first author and was completed by students in a math computer lab during the spring 2016 Calculus course at Borough of Manhattan Community College (BMCC) in the City University of New York (CUNY). The learning objective of this project was to guide students to use mathematical knowledge together with Maple technology to create artwork. The success of this project execution shed light on a success of PBL.

\section{Project Description}

The "World Culture Art Created with Calculus Graphs of Equations" poster project was assigned to students in Calculus class during the spring 2016 semester at BMCC in CUNY. Students were required to apply their graphing knowledge to create geometric cultural symbols. After selecting a country, students were required to create a geometric design that depicts the national symbol of that selected country and represents its culture. For example, if a student selected the United States, he/she might want to create a geometric design of the Statue of Liberty. A student selecting Canada might want to create a geometric design of a maple leave. If China was selected, a geometric design of a giant panda could be a student's first choice. The aim of this project was to show multi-cultural diveristy of the student body in CUNY.

In order to complete this project, students were expected to use graphing knowledge in Calculus as well as their prior knowledge in Algebra and Trigonometry. In Calculus, students were expected to use exponential functions, logarithmic functions, parametric functions, multi-variable functions, and polar equations. In Algebra, students were expected to use linear functions, quadratic functions, reciprocal functions, functions with absolute values, and others. In Trigonometry, students were acquired to use trigonometric functions as well as their corresponding inverse functions.

This 3-month project was completed in group in a math computer lab. The entire class was divided into small groups according to students' cultural interest. First, each group selected cultural symbols to represent the selected country as well as its culture. Second, each group composed different graphs of equations to generate sketches of the selected cultural symbols. Third, students produced digital images by using Maple technology in a math computer lab with lab technicians' assistance (see Appendix A). Forth, a poster template was designed and students' cultural art images were presented in a poster (see Figure 1). Finally, students' project work was evaluated by the created grading rubric (see Table 1).

\section{Methodology of Project Execution}

This project execution consisted of the following 4 phases.

\subsection{Cultural Symbols Selection}

In the first phase, students were guided on how to select typical national symbols that represent different countries as well as cultures. Students were encouraged to consider symbols from different perspectives, such as food, animals, plants, transportation vehicles, architectural buildings and religious items.

a. Food

Pizza was selected to represent Italian culture and hot dog was chosen to represent American culture by students.

b. Architectural Buildings

Architectural design varies in each country. The structural designs and architectural ornamentations are unique in each country. Three groups of students were interested in architectures. Sphinx figure and Pyramids were selected as monumental sculptures to represent early Egyptian civilization. Eiffel Tower was picked up as a cultural symbol of Paris. A Buddhist temple of Toji Pagoda was chosen to represent Japanese culture.

c. Plants

Plants have been used in celebration and rituals such as wedding, funeral, and many other ceremonies. One 
Vietnamese girl selected a lotus flower to represent Vietnam, since lotus flower is Vietnam's national flower. She mentioned that the beauty of lotus flower has often been cited in Vietnamese folk songs and poems. Another student who is from Canada selected Canadian Maple Leaf to represent Canadian culture.

\section{d. Animals}

Animal figures are often used to symbolize cultures. One Chinese student selected a giant panda to represent China. He explained that giant pandas show friendship and peace in Chinese culture. Similarly, a bald eagle was selected to represent America, as a symbol of strength and courage.

e. Transportation Vehicles

It is widely known that double decker buses originated in England. A student from England selected a double decker bus to represent English culture. Especially, a five-pointed star with strips was selected to represent United States Air Force.

\section{f. Religious Figure}

Religious iconography is found in many cultures. A Mexican student selected an image of Aztec Calendar (Sun Stone) to represent Mexico.

\subsection{Creation of Cultural Symbols by Math Equations}

In the second phase, students were taught on how to use graphs of equations and how to adjust parameter values in equations to generate sketches of selected cultural symbols.

\subsubsection{Equation of a Straight Line}

The fundamental knowledge of a linear equation $y-b=m(x-a)$ where $m$ is the slope of the line and $(a, b)$ is one point on the line, has been used by students as a basic skill in this project. In the shape of five-pointed military star in the United States Air Force image, students figured out location of 5 vertices and created 5 line segments by 5 linear equations listed as below:

$$
\begin{aligned}
y_{1} & =\tan \left(\frac{\pi}{5}\right)(x+10) \\
y_{2} & =\tan \left(\frac{2 \pi}{5}\right)(x+10) \\
y_{3} & =-\tan \left(\frac{\pi}{5}\right)(x-10) \\
y_{4} & =-\tan \left(\frac{2 \pi}{5}\right)(x-10) \\
y_{5}=10 \tan \left(\frac{\pi}{5}\right) & +5 \sqrt{1+\left(\tan \left(\frac{2 \pi}{5}\right)\right)^{2} \tan \left(\frac{\pi}{5}\right)}
\end{aligned}
$$

Linear equations were also used in the shape of triangles in an Egyptian Pyramid, triangles in the London Big Ben, a rectangular body of an England Double-Decker bus, and horizontal line segments at different heights in a five-story Japanese temple.

\subsubsection{Equation of a Circle}

An equation of a circle is $(x-a)^{2}+(y-b)^{2}=r^{2}$ with its center point $(a, b)$ and its radius $r$. This form of a circle equation has been used quite often in this project. For example, a circle representing a round clock in the London Big Ben was generated by $(x-18)^{2}+(y-4)^{2}=4$. An equation of the upper half of a circle as the shape of an umbrella depicts England rainy weather. In the creation of an Italian pizza, students created two concentric circles and used the area between two concentric circles to represent the pizza crust. Students also used a sequence of circle equations centered at different points with different radii to represent different pizza toppings, such as red circles for tomato, white circles for cheese, and black circles for mushroom. In designing Chinese Panda, students applied circle equations for the round shapes of panda's face, ears, eyes and nose. Many concentric circle equations were also used to construct the Mexica Aztec Calendar image.

\subsubsection{Equation of an Ellipse}

The standard equation of an ellipse is given by $\frac{(x-a)^{2}}{m^{2}}+\frac{(y-b)^{2}}{n^{2}}=1$ with its center point $(a, b)$ and the value of 
$x$-axis for $m$ and the value of $y$-axis for $n$. Ellipse equations were used in a hot dog image depicting American fast-food. The following two ellipse equations were used to generate an image of oval bread and an image of wrapped sausage respectively:

$$
\begin{aligned}
& \frac{(x-15)^{2}}{75}+\frac{(y-5.1)^{2}}{3}=1 \\
& \frac{(x-15)^{2}}{50}+\frac{(y-6.3)^{2}}{2}=1
\end{aligned}
$$

\subsubsection{Equation of an Exponential Function}

The standard equation for an exponential function is $y=a b^{x}$ with constant values of $a$ and $b$ where $b>0$ and $b \neq 1$. The upward increasing exponential curve for $b>1$ and downward decreasing exponential curve for $0<b<1$ were used by students in the architectural skeleton design of French Eiffel Tower. Students used the following 4 exponential equations to represent skeleton-frame of Eiffel Tower:

$$
\begin{gathered}
y_{1}=8 \cdot 8^{x} \\
y_{2}=1.5^{5.2} \cdot 1.5^{3 x} \\
y_{3}=1.5^{5.2} \cdot\left(\frac{8}{27}\right)^{x} \\
y_{4}=8 \cdot\left(\frac{1}{8}\right)^{x}
\end{gathered}
$$

\subsubsection{Equations of Trigonometric Functions}

The graph of a periodic water wave shape can be generated by trigonometric functions and inverse trigonometric functions. Students used the following two trigonometric functions to create the periodic waveform in the design of yellow mustard and red ketchup in a hot dog image:

$$
\begin{aligned}
& y_{1}=1.5 \sin \left(2 x-\frac{\pi}{50}\right)+5.3 \\
& y_{2}=1.5 \sin \left(1.5 x-\frac{\pi}{40}\right)+5
\end{aligned}
$$

\subsubsection{Equations for Polar Curves}

The graphing equations in polar forms were used in this project to create flower patterns. In particular, the polar equations for Rose curves are defined by $r=a \cos (n \theta)$ or $r=a \sin (n \theta)$. Students used several polar equations to produce cohesive multi-layered flower patterns. For example, in the picture of Vietnam's national Lotus flower, students applied 3 polar equations for 3 layers from inside to outside. Another example is an image of the Canadian Maple Leaf created by a polar equation

$$
r=\frac{100}{100+\left(\theta-\frac{\pi}{2}\right)^{8}}\left(2-\sin (7 \theta)-\frac{\cos (30 \theta)}{2}\right) .
$$

\subsection{Computer-Generated Images by Maple Technology}

In the third phase, students worked with Maple Software technology in a math computer lab to produce computer-generated images. The handout of a Maple Instruction Booklet was provided for students as scaffolding materials to acquire necessary technical knowledge. Students could ask for special training and hands-on personal assistance from lab technicians, if needed. For example, students learned how to use the Maple code of "display" to compose multiple graphing equations in a cohesive diagram. Students applied the Maple command of "axes=none" for deleting backgrounds of coordinate systems. Students used the color command to select their desired colors. Students used the Maple code of "filled=true" to paint images in color. Students used the maple code of "thickness=number" to adjust the thickness of figure outlines.

\subsection{Poster Template Design}

In the fourth phase, the poster template was designed after 12 pictures of cultural symbols were collected from 
students' work. The wreath design of the United Nation peace emblem was used in the poster template. 12 cultural images surrounded by the United Nation peace wreath present peace, respect, harmony, and unity of all people in the world.

\section{Project Outcomes and Assessments}

\subsection{Project Outcomes}

Students' artwork in the "World Culture Art Created with Calculus Graphs of Equations" poster is presented in Figure 1. In addition, 3 examples of students' work in maple codes can be found in Appendix A.

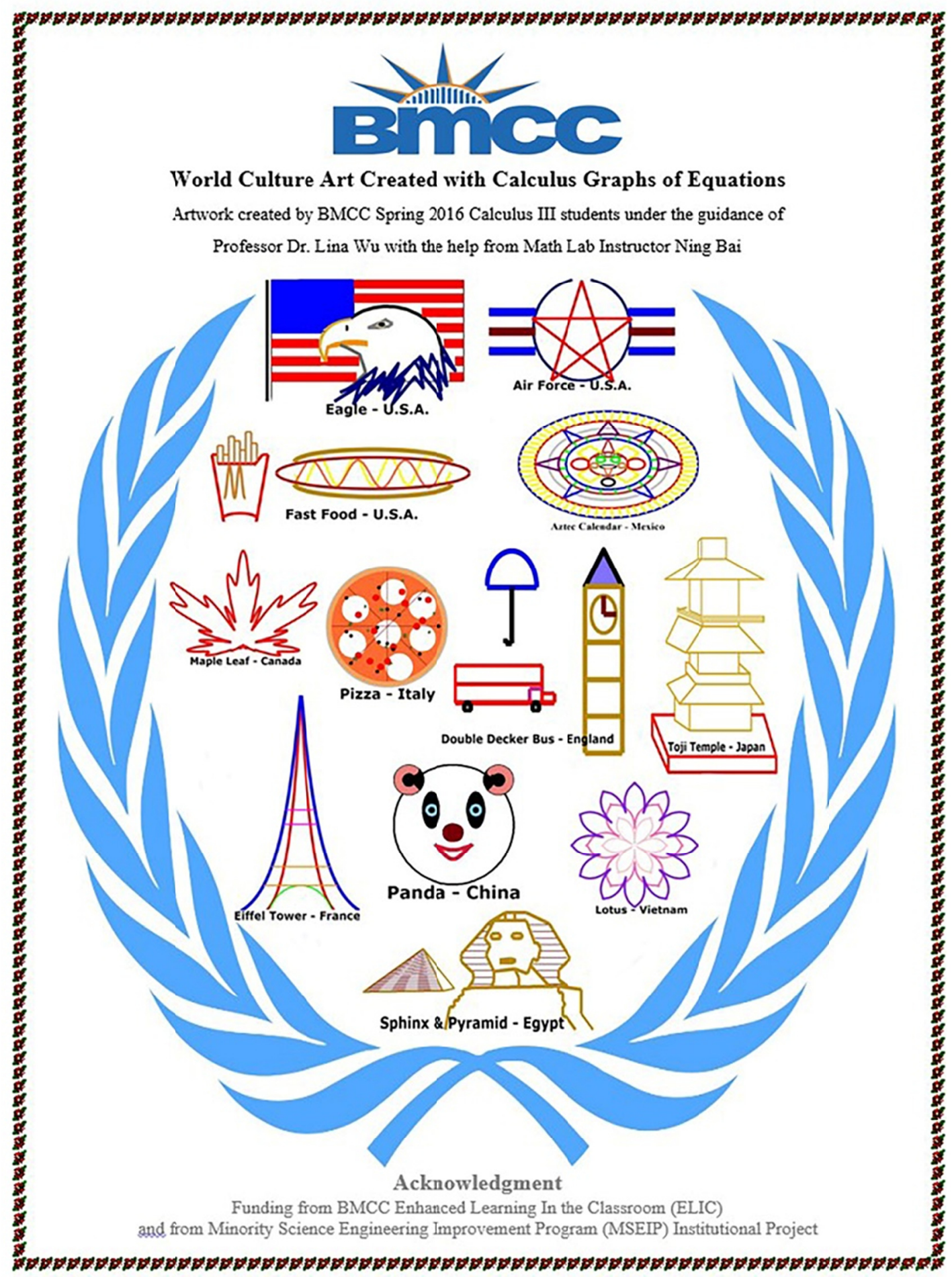

Figure 1. World Culture Art Created with Calculus Graphs of Equations 


\subsection{Project Assessments}

Two assessment methods were used to evaluate students' project work. The first assessment was their PowerPoint presentation. The second assessment was their written assignment. For one PowerPoint presentation on each cultural artwork, students were expected to describe their group work by answering the following questions:

1) What math equations did you use to generate each image of the desired cultural artwork? In particular, list all equations used in each artwork image. And indicate each equation that corresponds to a certain part of the artwork image.

2) What Maple codes did you use to produce a computer-generated image? More precisely, make a list of all Maple commands used in each artwork image. Demonstrate each Maple code's role in the creation of each digital artwork image.

3) What was the contribution made by each participant on the team?

Students' PowerPoint Presentation on each artwork image was graded by this following rubric:

Table 1. Rubric for each artwork in "World Culture Art Created with Calculus Graphs of Equations" poster

\begin{tabular}{|c|c|c|c|c|c|}
\hline $\begin{array}{l}\text { Component/Rating } \\
\text { by Points }\end{array}$ & $\begin{array}{l}\text { Excellent } \\
12 \text { points }\end{array}$ & $\begin{array}{l}\text { Good } \\
9 \text { points }\end{array}$ & $\begin{array}{l}\text { Fair } \\
6 \text { points }\end{array}$ & $\begin{array}{l}\text { Poor } \\
3 \text { points } \\
\end{array}$ & $\begin{array}{l}\text { Missing } \\
0 \text { point } \\
\end{array}$ \\
\hline $\begin{array}{l}\text { Demonstration of all Maple commands } \\
\text { for each computer-generated image }\end{array}$ & $\begin{array}{l}\text { correct commands } \\
\text { more than } 20\end{array}$ & $\begin{array}{l}\text { correct } \\
\text { commands } \\
\text { between } \\
10 \text { and } 20\end{array}$ & $\begin{array}{l}\text { correct } \\
\text { commands } \\
\text { between } \\
5 \text { and } 10\end{array}$ & $\begin{array}{l}\text { correct } \\
\text { commands } \\
\text { leass than } 5\end{array}$ & $\begin{array}{l}\text { incorrect } \\
\text { commands }\end{array}$ \\
\hline $\begin{array}{l}\text { Illustration of all math equations used for each } \\
\text { image creation }\end{array}$ & $\begin{array}{l}\text { correct equations } \\
\text { more than } 20\end{array}$ & $\begin{array}{l}\text { correct } \\
\text { equations } \\
\text { between } \\
10 \text { and } 20 \\
\end{array}$ & $\begin{array}{l}\text { correct } \\
\text { equations } \\
\text { between } \\
5 \text { and } 10\end{array}$ & $\begin{array}{l}\text { correct } \\
\text { equations } \\
\text { less than } 5\end{array}$ & $\begin{array}{l}\text { incorrect } \\
\text { equations }\end{array}$ \\
\hline $\begin{array}{l}\text { Explanation of each participant's contribution } \\
\text { in team work }\end{array}$ & $\begin{array}{l}\text { leadership work by } \\
\text { overcoming most } \\
\text { difficulty }\end{array}$ & $\begin{array}{l}\text { impressive } \\
\text { work }\end{array}$ & $\begin{array}{l}\text { complete } \\
\text { work with } \\
\text { poor quality }\end{array}$ & $\begin{array}{l}\text { incomplete } \\
\text { work }\end{array}$ & $\begin{array}{l}\text { no } \\
\text { contribution }\end{array}$ \\
\hline
\end{tabular}

After each PowerPoint presentation, students in each group were required to submit a written report to explain their answers of the above questions. Students were also required to include artwork images along with math equations and Maple commands in their report.

On each artwork image, students in each group received total of 50 points. On their PowerPoint presentation, students received 36 points and on their written report, students received 14 points. Each group completed 2 artwork images and students in each group received total of 100 points.

The Maple multi-cultures art project counted as $15 \%$ of the overall final grade in the Calculus course.

\section{Discussions of PBL Pedagogy and Maple Technology}

\subsection{Benefits of PBL to Students}

Working on this project has provided many benefits to students. First, students have been guided on how to apply their mathematical knowledge to create artwork. This project experience offers a new way for students to learn how mathematics can connect to art. Second, students have been taught on how to use Maple technology as an educational tool. Third, students have participated in this project by collaborating and cooperating with one another in structured group setting. Students have learned to share ideas with each other and work together in team. Forth, students' creativity, diversity, flexibility, and freedom in their math thinking have been fostered. Finally, students' project achievements have given them self-pride and confidence in learning.

\subsection{Challenges of PBL for Teachers}

Teachers will face challenges when they apply the PBL method as a teaching pedagogy. For example,

1) How to design an appropriate project to link theoretical knowledge with practical applications. The design of a realistic project in a course-based context is the key to success.

2) How to prepare scaffolding materials according to students' backgrounds. Teachers will need to provide supplementary materials to make students familiar with project information and project tools. 
3) How to set up a reasonable timetable for students to complete the project.

4) How to use a technology as an educational tool in completing the project.

5) How to collaborate with lab technicians. How to make the best use of a math computer lab to provide students sufficient training to gain necessary technical skills.

6) How to create a project evaluation rubric. The rubric as a multi-faceted assessment tool is used to evaluate students' performance to meet learning objectives.

\subsection{Maple Advantages}

With many functions in Maple used in teaching, students find it easy to learn. Maple provides understandable learning guides and clear information explaining how Maple program works. For example, one of the important Maple software features is to show users how to correct errors in Maple message window. In addition, Maple has all of the standard mathematical notations, symbols, formulars and equations that are used in college Calculus textbooks. Maple offers many technical tools to users. Tools that are often used are the dynamic visualization tool, the symbolic and numeric computation tool, the interactive communication tool and many other useful tools.

An excellent 3-D dynamic graphing feature and an interactive computerized communication program in Maple help users to create art designs through math knowledge. Maple enables students to see the changes they have made in their artwork from the changes they made on the math equations. Maple transfers students' math graphing knowledge to visualization of art images with instant feedbacks. It allows students to create their desired artwork by using their math knowledge. Maple has become an important technological tool of discovering art in mathematics.

\subsection{Conclusions}

The "World Culture Art Created with Calculus Graphs of Equations" poster project fostered students' creativity, heterogeneity, and excitement in math learning. Students showed their in-depth understanding of graphing knowledge when they successfully applied different types of graphing equations for the image creation in Maple Software. Students' achievement in this project shed light on a success of PBL pedagogy. PBL pedagogy as an active learning approach enhanced students' cognitive skills and practical skills. Group work in this project helped students to develop interpersonal communication skills. Incorporating projects into classroom teaching by PBL pedagogy has become one of the latest popular trends in education to reach students' full potential talents.

\section{References}

Ali, R., Akhter, A., Shahzad, S., Sultana, N., \& Ramzan, M. (2011). The impact of motivation on studemts' academic achievement in mathematics in problem based learning environment. International Journal of Academic Research, 3(1), 306-309.

Devitt, J. S. (1993). Calculus with Maple V. Belmont, CA: Wadsworth.

Edwards, B. S., \& Ward, M. B. (2004). Surprises from mathematics education research: Student (mis) use of mathematical definitions. The American Mathematical Monthly, 111(5), 411-424. https://doi.org/10.1080/00029890.2004.11920092

Furner, J. M., \& Berman, B. T. (2003). Review of research: math anxiety: overcoming a major obstacle to the improvement of student math performance. Childhood Education, 79(3), 170-174. https://doi.org/10.1080/00094056.2003.10522220

Goodnough, K., \& Cahsion, M. (2003). Fostering inquiry through problem-based learning. The Science Teacher, 70(9), 21-25.

Kilicman, A., Hassan, M. A., \& Husain, S. S. (2010). Teaching and learning using mathematics software "The New Challenge". Procedia-Social and Behavioral Sciences, 8, 613-619. https://doi.org/10.1016/j.sbspro.2010.12.085

Li, X., \& Li, Y. (2008). Research on students' misconceptions to improve teaching and learning in school Mathematics and Science. School Science and Mathematics, 108(1), 4-7. https://doi.org/10.1111/j.1949-8594.2008.tb17934.x

Mestre, J., Hart, D. M., Rath, K. A., \& Dufresne, R. (2002). The effect of web-based homework on test performance in large enrollment introductory physics courses. Journal of Computers in Mathematics and Science Teaching, 21(3), 229-251.

Niess, M. L. (2005). Preparing teachers to teach science and mathematics with technology: Developing a 
technology pedagogical content knowledge. Teaching and Teacher Education, 21(5), 509-523. https://doi.org/10.1016/j.tate.2005.03.006

SZ, S. N. A., \& Eng, L. S. (2005). Integrating problem-based learning (PBL) in mathematics method course. Journal of Problem-Based Learning, 3(1), 1-13.

Tarmizi, R. A., \& Bayat, S. (2010). Effects of problem-based learning approach in learning of statistics among university students. Procedia-Social and Behavioral Sciences, 8, 384-392. https://doi.org/10.1016/j.sbspro.2010.12.054

York, C., Hodge, A., \& Richardson, J. (2008). Web-based homework in university algebra courses: Student perceptions of learning and motivation to learn. In K. McFerrin, R. Weber \& R. Carlsen et al. (Eds.), Proceedings of Society for Information Technology \& Teacher Education International Conference (pp. 4618-4624). Association for the Advancement of Computing in Education (AACE).

Zerr, R. (2007). A quantitative and qualitative analysis of the effectiveness of online homework in first-semester calculus. The Journal of Computers in Mathematics and Science Teaching, 26(1), 55-73.

\section{Appendix A}

\section{Three Examples of Students' Work in Maple Codes}

a. Example of Eiffel Tower-France

$>$ with (plots):

$>\mathrm{a}:=\operatorname{plot}\left(2^{\wedge}\left(3^{*} \mathrm{x}+3\right), \mathrm{x}=3 . .3, \mathrm{y}=1 . .8\right.$, color $="$ red",thickness $\left.=8\right)$ :

$>\mathrm{b}:=\operatorname{plot}\left(2^{\wedge}\left(-3^{*} \mathrm{x}+3\right), \mathrm{x}=-3 . .3, \mathrm{y}=1 . .8\right.$, color $="$ red",thickness $\left.=8\right)$ :

$>\mathrm{c}:=\operatorname{plot}\left(1.5^{\wedge}\left(3^{*} \mathrm{x}+5.2\right), \mathrm{x}=-3 . .3, \mathrm{y}=1 . .8\right.$, color $="$ blue", thickness $\left.=10\right)$ :

$>\mathrm{d}:=\operatorname{plot}\left(1.5^{\wedge}\left(-3^{*} \mathrm{x}+5.2\right), \mathrm{x}=-3 . .3, \mathrm{y}=1 . .8\right.$, color="blue",thickness $\left.=10\right)$ :

$>\mathrm{e}:=\operatorname{plot}\left(\operatorname{sqrt}\left(1.8-\mathrm{x}^{\wedge} 2\right), \mathrm{x}=-1.8 . .8, \mathrm{y}=1.8 . .8\right.$, color $=$ "green", thickness $\left.=4\right)$ :

$>\mathrm{f}:=\operatorname{plot}(\operatorname{sqrt}(1.8), \mathrm{x}=-1.5 . .1 .5, \mathrm{y}=1.5 . .8$, color="DarkOrange",thickness $=4)$ :

$>\mathrm{g}:=\operatorname{plot}(2, \mathrm{x}=-1.2 . .1 .2, \mathrm{y}=1.2 . .8$, color $="$ DarkOrange",thickness $=4)$ :

$>\mathrm{h}:=\operatorname{plot}(3.5, \mathrm{x}=-0.7 . .0 .7, \mathrm{y}=0.7 . .8$,color="Fuchsia",thickness $=4)$ :

$>\mathrm{k}:=\operatorname{plot}(4, \mathrm{x}=-0.6 . .0 .6, \mathrm{y}=0.6 . .8$, color $="$ Fuchsia",thickness $=4)$ :

$>$ display (a,b,c,d,e,f,g,h,k);

b. Example of Fast Food-U.S.A.

$>$ with (plots):

$>\mathrm{f}:=(-7)^{*} \mathrm{x}+7$

$>\mathrm{a}:=\operatorname{plot}(\mathrm{f}, \mathrm{x}=0 . .5, \mathrm{y}=0 . .7$, color $=" \mathrm{RED}$, thickness $=15)$ :

$>\mathrm{g}:=7 * \mathrm{x}-28$;

$>\mathrm{b}:=\operatorname{plot}(\mathrm{g}, \mathrm{x}=0 . .5, \mathrm{y}=0 . .7$, color $=" \mathrm{RED}$, thickness $=15)$ :

$>\mathrm{c}:=\operatorname{plot}\left(\operatorname{sqrt}\left((1 / 3)-(1 / 7)^{*}(\mathrm{x}-2.5)^{\wedge} 2\right), \mathrm{x}=0 . .5, \mathrm{y}=0 . .7\right.$, color="RED",thickness $\left.=15\right)$ :

$>\mathrm{d}:=\operatorname{plot}(7, \mathrm{x}=0 . .0 .5, \mathrm{y}=0 . .7$, color $=" \mathrm{RED} "$,thickness $=15)$ :

$>\mathrm{e}:=\operatorname{plot}(7, \mathrm{x}=4.5 . .5, \mathrm{y}=0 . .7$, color="RED",thickness $=15)$ :

$>\mathrm{h}:=\operatorname{implicitplot}(\mathrm{x}=0.5, \mathrm{x}=0 . .1, \mathrm{y}=6 . .8$, color $=" \mathrm{GOLD}$, thickness $=10)$ :

$>\mathrm{i}:=\operatorname{plot}((20 / 13) * \mathrm{x}+(1 / 13), \mathrm{x}=3.75 . .4 .5, \mathrm{y}=6 . .7$, color="RED",thickness $=15)$ :

$>\mathrm{k}:=\operatorname{plot}(6, \mathrm{x}=0.5 . .3 .85, \mathrm{y}=6 . .7$, color $=" \mathrm{RED}$ ",thickness $=15)$ :

$>1:=$ implicitplot $(\mathrm{x}=1, \mathrm{x}=0 . .5, \mathrm{y}=6 . .8$, color $=" G O L D "$,thickness $=10)$ :

$>\mathrm{m}:=\operatorname{plot}(8, \mathrm{x}=0.5 . .1, \mathrm{y}=6 . .8$, color $="$ GOLD",thickness $=10)$ :

$>_{0}:=$ implicitplot $(\mathrm{x}=1.5, \mathrm{x}=1.25 . .2, \mathrm{y}=6 . .9$, color $=" \mathrm{GOLD}$, thickness $=10)$ :

$>\mathrm{p}:=\operatorname{plot}(7, \mathrm{x}=1 . .1 .5, \mathrm{y}=6 . .7$, color $=" G O L D "$,thickness $=10)$ : 
$>\mathrm{q}:=\operatorname{plot}(9, \mathrm{x}=1.5 . .2, \mathrm{y}=6 . .9$, color $=" G O L D "$, thickness $=10):$

$>\mathrm{r}:=$ implicitplot $(\mathrm{x}=2, \mathrm{x}=1.5 . .2, \mathrm{y}=6 . .9$, color="GOLD",thickness $=10)$ :

$>\mathrm{s}:=\operatorname{plot}(8.5, \mathrm{x}=2 . .2 .5, \mathrm{y}=6 . .9$, color $=" G O L D "$, thickness $=10)$ :

$>\mathrm{t}:=$ implicitplot $(\mathrm{x}=2.5, \mathrm{x}=2 . .2 .5, \mathrm{y}=6 . .8 .5$, color $=$ "GOLD",thickness $=10)$ :

$>\mathrm{u}:=\operatorname{plot}(7.5, \mathrm{x}=2.5 .3, \mathrm{y}=6 . .7 .5$, color="GOLD",thickness $=10)$ :

$>\mathrm{v}:=$ implicitplot $(\mathrm{x}=3, \mathrm{x}=2.5 . .3, \mathrm{y}=6 . .9 .5$, color="GOLD", thickness $=10)$ :

$>$ w: $=\operatorname{plot}(9.5, \mathrm{x}=3 . .3 .5, \mathrm{y}=6 . .9 .5$, color="GOLD", thickness $=7)$ :

$>\mathrm{A}:=$ implicitplot $(\mathrm{x}=3.5, \mathrm{x}=3 . .3 .5, \mathrm{y}=6 . .9 .5$, color $=" \mathrm{GOLD}$, thickness $=10)$ :

$>\mathrm{B}:=\operatorname{plot}(8.25, \mathrm{x}=3.5 . .4, \mathrm{y}=6 . .8 .25$, color="GOLD",thickness $=10)$ :

$>\mathrm{C}:=$ implicitplot $(\mathrm{x}=4, \mathrm{x}=3.5 . .4, \mathrm{y}=6.25 . .8 .25$, color="GOLD", thickness $=10)$ :

$>\mathrm{E}:=\operatorname{plot}\left(1.75^{*}(\sin (7 *(\right.$ theta-Pi $)))+4$, theta $=1.1 . .2 .95$, color $=" G O L D "$,thickness $\left.=14\right)$ :

$>\mathrm{F}:=\operatorname{plot}\left(3.9-\operatorname{sqrt}\left((2)-(1 / 25)^{*}(\mathrm{x}-15)^{\wedge} 2\right), \mathrm{x}=0 . .30, \mathrm{y}=0 . .10\right.$, color="DarkGoldenrod",thickness $\left.=20\right)$;

$>\mathrm{G}:=\operatorname{plot}\left(5.1-\operatorname{sqrt}\left((3)-(1 / 25)^{*}(\mathrm{x}-15)^{\wedge} 2\right), \mathrm{x}=0 . .30, \mathrm{y}=0 . .10\right.$, thickness $=15$, color="Firebrick");

$>\mathrm{H}:=\operatorname{plot}\left(5.1+\operatorname{sqrt}\left((3)-(1 / 25)^{*}(\mathrm{x}-15)^{\wedge} 2\right), \mathrm{x}=0 . .30, \mathrm{y}=0 . .10\right.$, thickness $=15$, color="Firebrick");

$>\mathrm{L}:=\operatorname{plot}\left(6.3+\operatorname{sqrt}\left((2)-(1 / 25)^{*}(\mathrm{x}-15)^{\wedge} 2\right), \mathrm{x}=0 . .30, \mathrm{y}=0 . .10\right.$, color="DarkGoldenrod",thickness=20);

$>\mathrm{M}:=\operatorname{plot}\left(1.5^{*}(\sin (1 *(2 *\right.$ theta-Pi $/ 50)))+5.3$, theta $=8 . .22$, thickness=9, color="YELLOW");

$>\mathrm{N}:=\operatorname{plot}((1.5 * \sin (1 *(1.5 *$ theta-Pi/40) $))+5$,theta $=8 . .22$, color="Tomato",thickness $=9)$;

$>\operatorname{display}(\mathrm{a}, \mathrm{b}, \mathrm{c}, \mathrm{d}, \mathrm{e}, \mathrm{h}, \mathrm{i}, \mathrm{k}, \mathrm{l}, \mathrm{m}, \mathrm{o}, \mathrm{p}, \mathrm{q}, \mathrm{r}, \mathrm{s}, \mathrm{t}, \mathrm{u}, \mathrm{v}, \mathrm{w}, \mathrm{A}, \mathrm{B}, \mathrm{C}, \mathrm{F}, \mathrm{E}, \mathrm{L}, \mathrm{M}, \mathrm{K}, \mathrm{N}, \mathrm{G}, \mathrm{H})$;

c. Example of Double Decker Bus-England

$>$ with (plots):

$>$ with(plottools):

$>\mathrm{a}:=$ implicitplot $(\mathrm{x}=1, \mathrm{x}=1 . .8, \mathrm{y}=0 . .2$, thickness $=15$, color="Red"):

$>$ b: $=$ implicitplot $(\mathrm{x}=8, \mathrm{x}=1 . .8, \mathrm{y}=0 . .2$, thickness $=15$, color $=" \operatorname{Red} ")$ :

$>\mathrm{c}:=\operatorname{plot}(2, \mathrm{x}=1 . .8, \mathrm{y}=0 . .2$, thickness $=15$, color="Red"):

$>\mathrm{d}:=\operatorname{plot}(1, \mathrm{x}=1 . .8, \mathrm{y}=0 . .2$, thickness $=15$, color $=" \operatorname{Red} ")$ :

$>\mathrm{e}:=\operatorname{plot}(0.5, \mathrm{x}=8 . .9, \mathrm{y}=0 . .0 .5$, thickness $=15$, color="Red"):

$>\mathrm{f}:=$ implicitplot $(\mathrm{x}=9, \mathrm{x}=1 . .15, \mathrm{y}=0 . .0 .5$, thickness $=15$, color="Red"):

$>\mathrm{g}:=$ implicitplot $(\mathrm{x}=7, \mathrm{x}=1 . .15, \mathrm{y}=0 . .0 .75$, thickness $=15$, color $=$ "VioletRed"):

$>\mathrm{h}:=\operatorname{plot}(0.75, \mathrm{x}=7 . .8, \mathrm{y}=0 . .0 .75$, thickness $=15$, color="VioletRed"):

$>\mathrm{k}:=\operatorname{plot}(0, \mathrm{x}=1 . .9, \mathrm{y}=0 . .0 .05$, thickness $=20$, color $=" \operatorname{Red} ")$ :

$>\mathrm{c} 1:=\operatorname{circle}([2,-0.25], 0.25$, thickness $=20)$ :

$>$ c2: $=\operatorname{circle}([7.5,-0.25], 0.25$, thickness $=20)$ :

$>\mathrm{j}:=$ implicitplot $(\mathrm{x}=12, \mathrm{x}=0 . .12, \mathrm{y}=0 . .9$, thickness $=20$, color="DarkGoldenrod"):

$>1:=$ implicitplot $(\mathrm{x}=15, \mathrm{x}=0 . .15, \mathrm{y}=0 . .9$, thickness $=20$, color $=$ "DarkGoldenrod"):

$>\mathrm{m}:=\operatorname{plot}(2, \mathrm{x}=12 . .15, \mathrm{y}=0 . .1$, thickness $=20$, color $=$ "DarkGoldenrod"):

$>\mathrm{n}:=\operatorname{plot}(4, \mathrm{x}=12 . .15, \mathrm{y}=0 . .9$, thickness $=20$, color $=$ "DarkGoldenrod"):

$>0:=\operatorname{plot}(6, \mathrm{x}=12 . .15, \mathrm{y}=0 . .9$, thickness $=20$, color $=$ "DarkGoldenrod"):

$>\mathrm{p}:=\operatorname{plot}(9, \mathrm{x}=12 . .15, \mathrm{y}=0 . .9$, thickness $=20$, color $=$ "DarkGoldenrod"):

$>$ c3:=circle([13.5,7.5],1,thickness $=15$, color="DarkGoldenrod"):

$>\mathrm{q}:=$ implicitplot $(\mathrm{x}=13.5, \mathrm{x}=13 . .13 .5, \mathrm{y}=7.5 . .8 .5$, thickness $=20)$ :

$>\mathrm{r}:=\operatorname{plot}(7.5, \mathrm{x}=13.5 . .14 .5, \mathrm{y}=7.5 . .8 .5$, thickness $=20)$ :

$>\mathrm{s}:=$ plots[display](plottools[polygon]([[12,9], [15,9], [13.5,11]]),color="LightSlateBlue",thickness=20): 
$>\mathrm{t}:=\operatorname{plot}(0, \mathrm{x}=12 . .15, \mathrm{y}=0 . .0 .25$, thickness $=20$, color="DarkGoldenrod" $)$ :

$>\mathrm{A}:=\operatorname{plot}\left(\left(\operatorname{sqrt}\left(4-(\mathrm{x}-18)^{\wedge} 2\right)\right)+4, \mathrm{x}=0 . .20\right.$, thickness=20, color="Blue" $)$ :

$>\mathrm{B}:=\operatorname{plot}(4, \mathrm{x}=16 . .20, \mathrm{y}=0 . .9$, thickness $=20$, color="Blue" $)$ :

$>\mathrm{C}:=\operatorname{implicitplot}(\mathrm{x}=18, \mathrm{x}=18 . .19, \mathrm{y}=1 . .4$,thickness=20, color="Black"):

$>\mathrm{E}:=\operatorname{implicitplot}(\mathrm{x}=17.5, \mathrm{x}=0 . .21, \mathrm{y}=1 . .1 .25$,thickness=20,color="Black"):

$>\mathrm{F}:=\operatorname{plot}(1, \mathrm{x}=17.5 . .18, \mathrm{y}=0 . .9$, thickness $=20$, color="Black" $)$ :

$>\operatorname{display}(\mathrm{a}, \mathrm{b}, \mathrm{c}, \mathrm{d}, \mathrm{e}, \mathrm{f}, \mathrm{g}, \mathrm{h}, \mathrm{k}, \mathrm{c} 1, \mathrm{c} 2, \mathrm{j}, \mathrm{l}, \mathrm{m}, \mathrm{n}, \mathrm{o}, \mathrm{p}, \mathrm{c} 3, \mathrm{q}, \mathrm{r}, \mathrm{s}, \mathrm{t}, \mathrm{A}, \mathrm{B}, \mathrm{C}, \mathrm{E}, \mathrm{F})$;

\section{Copyrights}

Copyright for this article is retained by the authors, with first publication rights granted to the journal.

This is an open-access article distributed under the terms and conditions of the Creative Commons Attribution license (http://creativecommons.org/licenses/by/4.0/). 